\title{
The Economic Crisis is a Crisis for Economic Theory*
}

\author{
Alan Kirman ${ }^{\dagger}$ \\ †GREQAM, Université Paul Cézanne, EHESS, IUF. e-mail: kirman@univmed.fr
}

\begin{abstract}
This article examines, in the light of recent events, the origins of the difficulties that current macroeconomic models have in encompassing the sort of sudden crisis which we are currently observing. The reasons for this are partly due to fundamental problems with the underlying General Equilibrium theory and partly to the unrealistic assumptions on which most financial models are based. What is common to the two is that systematic warnings over more than a century in the case of finance and over 30 years in the case of equilibrium theory have been ignored and we have persisted with models which are both unsound theoretically and incompatible with the data. It is suggested that we drop the unrealistic individual basis for aggregate behaviour and the even more unreasonable assumption that the aggregate behaves like such a 'rational' individual. We should rather analyse the economy as a complex adaptive system, and take the network structure that governs interaction into account. Models that do this, of which two examples are given, unlike standard macroeconomic models, may at least enable us to envisage major 'phase transitions' in the economy even if we are unlikely to be able to forecast the timing of their onset. (JEL codes: B22, D84, D85, E10, E44)
\end{abstract}

Keywords: Crisis, general equilibrium, forecasting, networks, complex system.

\section{Introduction}

The world has recently been shaken by an upheaval in the financial sector comparable to that of 1929. These events in world financial markets have, to say the least, given economists pause for reflection. It is worth giving a schematic account of the unfolding of this crisis to see how it can be reconciled with standard economic theory or whether a serious rethinking of our theory is called for. Various explanations have been given for the origins of the collapse. One argument is that the Fed simply kept interest rates too low and this made it too easy for indebtedness to rise to unprecedented levels. Some argue that deregulation of financial institutions permitted excesses, while some others argue that government policy which encouraged even the poor to aspire to own their own homes was a major factor in the housing bubble. Yet another factor has been the high propensity to save in China (see Warnock and Warnock 2006). Another argument often heard is that banks became heavily overleveraged and they and their clients were very vulnerable to a downturn in underlying asset

* The CESifo Economic Studies Conference on 'What's Wrong with Modern Macroeconomics?' Munich, 6-7 November 2009.

(C) The Author 2010. Published by Oxford University Press

on behalf of Ifo Institute for Economic Research, Munich. All rights reserved.

For permissions, please email: journals.permissions@oxfordjournals.org 
prices (see Shin 2009). ${ }^{1}$ Whatever the origins of the problem, one can give a simple and persuasive account of the evolution of the crisis. Individual banks extended credit to those wishing to buy homes with less and less regard for the capacity of the borrowers to pay. If the unhappy borrower did not fulfil his obligations the bank recovered the home, the price of which was rising. Despite the cost of foreclosure, the underlying asset guaranteed that the loss for the bank was not important. This led to a rapid expansion in housing loans. The loans in question were distributed among banks worldwide, through instruments which packaged loans of varying quality together. This, we were told, was a good thing because it diversified the risk. However, with a weakening of the US economy the number of defaulters grew and, worse, prices in the housing market no longer rose. At this point, banks started to examine their positions and to evaluate the losses and potential losses due to the 'subprime' loans contained in the instruments they were holding. The problem was not only that some of the loans contained in the derivatives were 'toxic', that is, they were either liable to default, or had already done so, but it was also that the market's evaluation of all these instruments declined. Thus, the very presence of toxic assets, even when unidentified, dragged the price of all the derivatives down. Many major banks found that their positions were more than delicate and began to seek ways of redressing them. However, the crucial problem was that banks did not know which of their counterparts were in trouble and thus stopped lending to other banks. The freezing of the interbank market brought the whole system to a halt since banks are constantly in need of being able to finance various transactions and habitually borrow from each other to do so. Furthermore, as a result, not only banks but individuals and firms also found themselves unable to borrow, just as Bernanke (1983) suggests was the case after $1933 .^{2}$

As I have described it, it seems that the crisis has been essentially a liquidity crisis, in the sense that banks were unable to realize the sales of their assets necessary to cover the losses that they had made. Thus while they were not technically insolvent they were, at least temporarily, in difficulty. However, many have argued that the crisis has also been, in fact, about solvency issues ${ }^{3}$ and that many of the major actors were not in a temporarily illiquid situation but were, to all intents and purposes,

1 The key role played by leverage has been emphasized by Shleifer and Vishny (1997) and later by Gromb and Vayanos (2002), and Geanakoplos (2010) who has developed the idea of a leverage cycle.

2 It is worth noting that Bernanke does not explain the origins of the original crisis but considers the freezing of the credit market as being the result of the increase in the cost of intermediation, which he argues were a consequence of the crisis.

3 I am grateful to the referee for pointing this out. 
insolvent. In fact, Fostel and Geneakoplos (2008) argue that many banks were not prepared to declare a loss in the principle associated with a loan since they would have then been obliged to write their assets down and thus advertise their potential insolvency. This increased the uncertainty in the interbank market. But, inevitably, it became apparent that some banks and insurance companies were indeed, insolvent. This meant that the insolvent institutions had to be allowed to fail or had to be bailed out. The first option was what led to accepting the demise of Lehman Bros. The consequences of this on market expectations led to a different approach. Here again, one is led to ask could the failure of Lehman be regarded as a proximate cause of the crisis? My argument is that this event was an integral part of the way the system was evolving. The fact that it led to a change in policy-makers' strategy can be regarded as reflecting an initial underestimation of its impact.

The solution then adopted, which may, or may not, have eliminated or reduced the problem, was to inject enormous amounts of money into the system, to increase liquidity. The solutions to the insolvency problems included the rescue of AIG, the world's largest general insurance company whose credit-default swaps underpinned the credit market, and the decision to essentially guarantee the bad debt. In addition, the two largest mortgage banks in the USA were effectively nationalized. Several banks in Europe were rescued from bankruptcy and, to all intents and purposes, nationalized. Again, in each of these cases, one can point to specific problems. In the case of AIG, for example, the inadequate supervision by the Office of Thrift Supervision is frequently mentioned as a part of the explanation of the difficulties that the insurance company came to face. Yet my main argument is that all the components of the crisis were highly correlated and that it was the evolution of the system as a whole that led to its downfall. To decompose it into its components and to seek individual explanations for each of them, seems to miss the basic point. In any event, the crisis has had global consequences and an important impact on the real economy. Despite the concerted efforts of the major central banks and governments, it is far from clear how long the consequences will last.

Yet, there are signs that, at least financial markets, are inclined to shrug the crisis off and to assume that we will be back on track again rather soon. There are several points worth making about this. First, before macroeconomists were faced with the crisis there was a general consensus that we now understood the fundamental mechanisms of macroeconomics and that models such as the Dynamic Stochastic General Equilibrium (DGSE) model were a good representation of the macroeconomy. This model is an applied general equilibrium model that is considered as more scientific than earlier models since it is based on microeconomic foundations. I will come back to this later, but suffice it to say 
that the widespread use of this sort of model coincided with the growing belief that our understanding of the functioning of the economy had greatly advanced.

To cite two leading figures, Robert Lucas in his 2003 presidential address to the American Economic Association said that the "central problem of depression-prevention has been solved', and in 2004, Ben Bernanke, chairman of the Federal Reserve Board, celebrated the 'Great Moderation' in economic performance over the previous two decades. This he attributed, in part, to improved economic policy making resulting from a better understanding of the functioning of the economy. The vocal and publicly audible criticisms of Krugman (2009a), Shiller (2003, 2006) and Stiglitz (2003) were dismissed as attacks based on an insufficient understanding of the powerful tools that were being employed. Second, there has been another type of reaction, (see, e.g. Reinhart and Rogoff 2009), which points out that crises are a recurrent phenomena and that there is nothing particularly special about this one. It seems to me that this merits a comment. If the DSGE proponents have got it right, then they should be able to explain why their models do not allow for the possibility of a crisis of the sort that we are currently facing. Indeed this applies to all macroeconomic models, for if major crises are a recurrent feature of the economy then our models should incorporate this possibility. In fact, a careful reading of Reinhart and Rogoff (2009) reveals that all that they are suggesting is that there are common characteristics of all major downturns in financial markets. However, they do not suggest a model which would generate these downturns

The sketch that I gave of the onset of the crisis is a story of contagion, interdependence, interaction, networks, and trust. Yet, as I have observed, these notions are not features of modern macroeconomic models. A first line of defence offered by economists to justify this, is that we are talking about financial markets here and that these are intrinsically different from the rest of the economy, even if the two interact. But is this really the case? Whether we are talking about models of financial markets or of the real economy, our models are based on the same fundamental building blocks. The most important of these is the idea that individuals act in isolation and the only interaction between them is through the price system. All that we have to do, to deduce the behaviour of the economy at the aggregate, or macro level, is to add up the behaviour of the individuals who make it up. Furthermore, the theoretically unjustified assumption is made that the behaviour of the aggregate can be assimilated to that of an individual.

Economists are not alone in making this unwarranted assumption. Both politicians and commentators use explanations such as the market was afraid of the oncoming recession' to justify a fall in prices, or that 'the newly published growth forecast made the market more optimistic', 
as if the market viewed the world with one mind. Yet, the idea of explaining the collective panics or collective 'exuberance', to use Alan Greenspan's famous phrase, that we periodically observe, as reflecting the identical, or average behaviour of individuals who neither contact nor observe those around them, seems curious. One possible view is that the recent near-collapse of the world's banking system corresponds to the collective result of individual banks optimizing in isolation, but unconsciously coordinating on a disastrous solution. There is some truth in this, for banks were surely not consciously choosing the aggregate outcome that actually materialized. However, what is involved is more subtle. There is, in markets and in financial markets in particular, a great deal of local interaction, of transmission of information, views, and expectations from one actor to another. Large systems with micro characteristics of this sort are studied in physics, biology, and also sociology. It has long been recognized in other disciplines that a system may switch rapidly from one phase to another and that this will be dependent on its internal organization and not on some major exogenous shock. The standard example of such a phase transition is that of heating water, which yields a sudden change, in the state of the water, at boiling point. The volume changes in a discontinuous way even though the change in temperature is continuous. Thus, although there is an external change which triggers this transition, it is not a major one. While this sort of example seems far from economic systems, the simple application of the Ising model from physics, to voters provides a more familiar application. In this model, voters are influenced by their neighbours. They look at the opinion of the majority of their neighbours and vote accordingly. The system converges to a state in which all of the voters vote for the same alternative. However, now suppose that individuals follow the majority of their neighbours with a certain probability. In this case, the result of the deterministic model will still hold, until a certain critical value of that probability is attained. Then, suddenly the voters will have mixed opinions which will fluctuate over time. Once again the trigger is a small change, the size of which is quite unrelated to the importance of its consequences.

The uncomfortable thing about models of the sort of system that I am referring to, is that there is no necessary proximate major cause for a sudden shift in the aggregate state. Similarly, in social or economic situations, when a major and sudden change occurs in the state of the aggregate economy, there are no culprits to blame and no easy remedies to prevent similar occurrences in the future. If we stick to the physical analogy there is no warning that the system will go through a phase transition. There is, of course, an alternative view which might be more appealing for economists. It is that the system may reorganize itself in such a way that it becomes vulnerable to small changes in the environment. Neither of 
these alternatives is encompassed by modern macroeconomic models. The relations between the variables are essentially fixed and the system functions at equilibrium in a very mechanical way. The only thing that may perturb the evolution of the economy is an external shock from which the economy adjusts, by assumption, to a new equilibrium. How it does so is typically not analysed. Out of equilibrium, dynamics are not a central issue in economics and Gerard Debreu said explicitly that their analysis was too difficult and that was why he had never ventured in that direction. ${ }^{4}$ So, the most interesting aspects of economics, if the economy is viewed as a complex interactive and adaptive system, are absent in macroeconomic models based on the General Equilibrium view (for an interesting discussion of the role of the equilibrium notion in economics, see Farmer and Geanokoplos 2009).

In other words, the vision of the world reflected in modern macroeconomic models, leaves out aspects of the economy which seem to be central to understanding how it functions and evolves. Indeed, the problem that intrigues many people when they first come to economics is that of explaining how the myriad of disparate individual economic activities come to be coordinated. A modern economy is composed of millions of agents who interact directly and indirectly with each other. Each of them knows a great deal about the activities they are engaged in and a lot about the people whom they interact with on a regular basis. They interact intensively and directly with some individuals and less often and more indirectly with others. They have a great deal of very local information but know much less about the behaviour of the whole economy, other than through some summary statistics. Yet, despite the fact that most of the individuals in the system are not aware of each other's existence, their activities collectively are remarkably coordinated. The questions that we should be asking are, first, how is it that all these individuals, each of them with specific information and abilities, organize themselves, for most of the time, in a consistent and relatively predictable way? This is the question of 'self-organization', one which was central to Hayek's thinking (see Hayek 1945).

Second, how is it that the system passes periodically through major upheavals? These problems, rather than the problem of how efficient are the states that the economy arrives at, seem to me to pose the central questions for macroeconomists. While the economic system and, in particular, the financial system may give the impression that it is functioning well, from time to time it may slide into a totally different state. What

4 He made this observation in an interview in 1992 with E. R. Weintraub; See Weintraub (2002). 
I would argue is that such movements are intrinsic and not due to some exogenous shock. The movement and changes in the system do indeed, come from the, at least locally, purposeful behaviour of the individuals who make up the system. However, none of them can really be held responsible for radical changes in the aggregate economy. As Voltaire said, 'In an avalanche no single snowflake feels itself to be responsible.'

Indeed, even though the structure of the economy may be quite robust, what I would argue is that the system will evolve and may occasionally go through very large changes, which would not be consistent with a static equilibrium, nor a steady state, view. Furthermore, I would suggest, for example, that what we are observing are not efficient situations in any sense. A great deal is being achieved in terms of coordination but there is almost always room for improvement in every direction, as Schumpeter (1950) firmly believed. Let me come back to the recent 'credit crisis', which illustrates this well.

From a situation where many dimensions of the world economy seemed to have achieved some degree of stability, we were suddenly precipitated into what, as I have mentioned, has been described as the "worst crisis since 1929'. Did this happen as the result of some major shock to the economy or the arrival of some significant unanticipated news? I would argue that this was not at all the case. Sornette (2003) makes the same point, that a stock market crash is not the result of short-term exogenous events, but rather involves a long-term endogenous buildup, with exogenous events acting merely as triggers (see also Johansen and Sornette 2006). In particular, he shows that financial crashes are the result of the 'spontaneous emergence of extreme events in self-organizing systems', and observes that 'extreme events are characteristic of many complex systems'. This echoes Minsky's (1982) reflection on the 'disruptive internal processes' in the economy. How, in economic terms could this happen? What was occurring was that norms had developed and become established. In adopting these norms, the individuals were probably unconscious of their aggregate consequences. In the case of the financial crisis, the rules of the game were gently modified in the banking sector. It became acceptable to lend to people who had little chance of being able to repay their loans, it became acceptable to use more and more leveraged positions, and it became standard practice to hive off dubious loans in the form of derivatives with the argument that the risk was being 'diversified'. Yet, the benefit from diversifying risks depends crucially on the distribution of the returns on those assets; I will come back to this later. All of this happened because the actors saw others acting in a certain way and being successful and therefore imitated their behaviour, not because they had reappraised their own portfolio and changed their estimate of its riskiness. 
However, this slow and almost unconscious shift was at the root of the crisis. Yet, as more and more risky loans were issued in a world where house prices were booming, nobody saw this as a real problem. The practices in question became standard procedure and this, at the very micro level, made them acceptable. Furthermore, through the dispersion of these risks through derivatives throughout the global banking sector there was seen to be no systemic threat. Indeed, with rare exceptions, (see Freixas et al. 2000), little attention was paid to systemic risk in the banking sector until very recently. As May and Arinaminpathy (2009) point out,

'The joint study on New directions for understanding systemic risk' (Kambhu et al. 2007) put together by the US National Academy of Sciences and the Federal Reserve Bank of New York was motivated by the observation that, although much effort and sophisticated analyses were increasingly directed to maximizing returns with minimum risk for individual banks and investment firms, essentially no attention was being paid to studying the concomitant changing dynamics of the entire system, that is, to study 'systemic risk'.

The individuals or banks making the decisions were not aware that their increasingly interdependent positions were generating a threat to the stability of the whole system. In fact, the individual actors all felt themselves to be well protected having, in effect, insured their positions with others. There was no central mind to perceive this. The system, indeed, as Hayek (1989) argued, was always organizing itself. However, this self-organization, contrary to a standard and largely ideological view, was not stabilizing. Indeed, as I have said, it needed only a small downturn in the property market for banks to start becoming concerned about who was holding the bad risks. As soon as this happened, banks became wary of lending to each other and the interbank credit market dried up. This in turn led to a shortage of credit for firms and individuals. To repeat, the system froze, not as a result of some single specific event but as a result of a series of related occurrences, and without the actors in the system having foreseen the collective result of their individual actions.

The situation was saved, as I have said, as far as the liquidity problems went, at least temporarily, by massive injections of liquidity but not without solvency problems having led to the effective failure of some banks, and certainly not without with major consequences for the real economy. But, what is important is that the measures taken were purely pragmatic, and often orthogonal to both what models would have suggested and to ideological convictions. The only explanation given by those taking the decisions was that 'in exceptional times we need exceptional measures'. But it is difficult to put much confidence in measures which are taken neither on theoretical grounds nor on any well-defined policy view. 
What it seems to suggest is that those taking the decisions have little understanding of how the system really functions and evolves and that the models which they or those who advise them use, are simply too detached from reality. Thus, in difficult times, theory is put to one side and it is replaced by pragmatic judgement.

How does the actual evolution of the economy compare with that of the sort of view that I believe we should develop? First, the economy and the financial sector had organized itself into a highly interdependent system. This is not, however, reflected in the structure of modern macroeconomic models. Second and paradoxically, the financial sector ceased to play its essential role of matching the providers of capital with those who demand it, in an informationally efficient and transparent way. Indeed, the extensive interlocking of the components of the financial and housing markets and the heavy trading of derivatives actually concealed information rather than revealing it. The diversification and repackaging of the assets in question made it more and more difficult to estimate the true risk involved, and the dependence on the evolution of the prices in the housing market meant that there was an important correlation between the risks of the individual assets. Worse, when the housing market went into decline, the way in which derivatives had been constructed made it very difficult for the lenders to restructure their loans in a way which would have been advantageous for both banks and borrowers (see Geanakoplos 2010). Thus, the system self-organized its own destruction and led to a radical change in the aggregate economic situation. But once again, this is a story of interaction and interdependence and the breakdown of the relations of trust and confidence which had developed over time and not one of an external shock to a stable market.

What is important to emphasize again, at this juncture, is that the fact that there is no clear separation between financial markets and the 'real economy' produced many of the problems in the banking sector. This is something which, almost by definition, does not show up, or rather is absent from, most macroeconomic models. In the evolution of the drying up of the credit market, an important role was played by major corporations drawing on existing credit lines and thereby exacerbating the situation. As Ivashina and Scharfstein (2010) explain, these credit-line drawdowns were part of the 'run' on banks that occurred at the height of the crisis. Unlike old-style bank runs, instigated by uninsured depositors when there was no deposit insurance, this bank run was instigated by short-term creditors, counterparties, and borrowers who were concerned about the liquidity and solvency of the banking sector. In other words, concerns about the financial sector led actors in the economy to behave in a way which reinforced the crisis. So, the evolution of the crisis involved in a crucial way, the interdependence of the real and the financial economies. 
To explain this evolution, the question is not to see how the economy moved away from, and might then return to, an equilibrium in the classic sense, it is rather to understand what sort of framework it had developed to achieve all of the coordination and interdependence that we did observe. Then, and more importantly, we have to explain how that self-organization and the contagious reaction of the components could lead to a major phase change. There are therefore two levels on which to argue. On the one hand, we would like to explain how all the agents in the economy come to coordinate their daily activities in a relatively stable fashion even though this may not correspond to an equilibrium in the standard sense. On the other hand, we have to explain how a system functioning in this way, once again with no central authority to control it, can suddenly evolve into a crisis?

\section{The evolution of macroeconomic theory}

In what follows, I briefly present the aspects of macroeconomic theory which, in current models, seem to me to be incomplete or erroneous and try to explain how we came to develop models which have these problems. The basic argument starts with the fact that macroeconomic theory has insisted on having 'sound micro-foundations' and I argue that this has taken us down the wrong road. I discuss the problem of aggregation and then turn to that of information. Then I look at the 'efficient markets' hypothesis, and in particular, its historical origins and why, as Alan Greenspan (2008) remarked recently, this intellectual edifice collapsed. Finally, so as not to simply join the critical chorus, I offer some suggestions as to what would be a good basis for macroeconomic theory and mention two models which provide a basis for an alternative analysis.

\section{A more 'scientific' macroeconomics and the aggregation problem}

Macroeconomic theory took a major turn when it was argued that models of aggregate phenomena had to be based on 'sound micro foundations'. In other words, the basic building blocks have to be agents, each of whose behaviour is based on the classical axioms of rationality which we impose on those agents in standard theory. It was no longer acceptable to study relationships between aggregate variables without individual behavioural foundations. But to take this route means examining the aggregation problem. How can we aggregate individual behaviour in such a way that the result is analytically tractable and has the sort of properties 
that a macroeconomist needs? The problem of how we pass from the individual level to the aggregate level has been largely discussed in the literature (see e.g. Stoker 1995), and in the past those who had been brought up in the General Equilibrium tradition considered the field of macroeconomics as essentially corresponding to the aggregate behaviour of a model based on rational optimizing individuals. What is referred to as Walrasian macroeconomics ${ }^{5}$ may thus be thought of as taking individual utility or profit maximizing behaviour and translating it to the aggregate level. Now, for reasons which I will explain, to avoid the aggregation problem, the aggregate data is usually treated in macroeconomics, as if it were the result of one individual's decisions. This, as will soon become apparent and is well known, is not legitimate from a theoretical point of view but has not prevented macroeconomists from continuing along this path.

Those who take this route ask what meaningful relationships between the aggregate variables of the economy can be established starting from a set of independent utility maximizing individuals. But, they make the further and crucial assumption that the aggregates in question can be considered as resulting from one aggregate, or average, rational individual's choices. This has not always been the case. Many earlier macroeconomists were content to specify the relations between aggregate variables and to test them without having recourse to models of individual behaviour. It was nevertheless common practice to invoke individual decisions as a way of justifying the assumptions made about the macroeconomic relations. This explains the famous remark that ' $70 \%$ of Keynes' General Theory is microeconomics'. Indeed, in the most sophisticated modern macroeconomic model, the DSGE synthesis, to which I have already referred, the aggregation problem is not solved, just treated as if it were solved.

Where does this leave us? Either we continue to try to reconcile aggregate behaviour with that of the standard rational individual, a hopeless task from a theoretical point of view, or we accept that the difference between individual and aggregate behaviour is fundamental and then build models which show this explicitly. Thus aggregation should not be assumed away but has to move to the centre of the stage. I would therefore argue that, since aggregate behaviour does not correspond to that of a 'rational individual' we have to model markets or economies as complex adaptive systems so that we can make progress in explaining aggregate economic phenomena.

5 Whether this is appropriate or not as an appellation can be judged by looking at Donald Walker's (2006) 'Walrasian Economics'. 
Thus the really basic issue is that we continue, in much of macroeconomic analysis, to dismiss the aggregation problem and to treat economic aggregates as though they correspond to rational economic individuals although this is theoretically unjustified. It is this simple observation that makes the structure of the models, however sophisticated, which macroeconomists build, unacceptable. But what is worse is that in the anxiety to preserve the scientific foundations, macroeconomists also dismiss the questioning of the soundness of those foundations. Such questioning comes from behavioural economics and explicitly casts doubt on the idea that individuals themselves do behave according to the standard 'sound microfoundations'. This is very far from new; Pareto devoted a whole chapter of his Treatise on Sociology to what he described as 'non-rational behavior' (Pareto 1916). From Simon (1957) onwards, many have suggested that individuals reason in a limited and local way. Experiments, observation, and examination of the neural processes utilized in making decisions all suggest that homo economicus is not an accurate or adequate description of human decision making. ${ }^{6}$ But then one might reasonably ask why macroeconomists insist on their 'representative agent' models if the representative agent is assumed to be more rational than those he represents.

\section{Uniqueness, stability and the 'representative agent'}

To see what is going on, suppose for the moment that we put to one side the debate as to what constitutes rationality and that we accept the standard axioms of rationality for economic agents and wish to build our macromodels on that basis. Why would this pose a problem? The simple answer is that, even under these very restrictive assumptions, there is no guarantee that the economy would ever attain the equilibrium states which are analysed in such detail by macroeconomists. In other words, the key to the problem lies in the stability of the equilibrium states. We make the usual rationality assumptions for our individuals because this enables us to prove the existence of equilibrium states. These can be shown to be characterized by an efficient allocation of resources by the well-known 'fundamental theorems of welfare economics'. It is often asserted that somehow, an economy in equilibrium, if knocked out of that state, will return to it, as a result of some adjustment process. Typically, the Walrasian tatonnement process, which increases

6 For good surveys of the relevant literature, see Rabin (1998), Camerer et al. (2004), and Angner and Loewenstein (2010). 
the prices of those goods for which demand exceeds supply and decrease the prices of those for which the opposite is true, has been used as an example. Let us assume for a moment that we define some such process, which adjusts prices when they are not in equilibrium. This would not help us at all, because the fundamental problem is that the conditions which are known to guarantee the stability of such a process cannot be obtained from assumptions on the behaviour of the individuals. To be absolutely clear, what Sonnenschein (1972), Mantel (1974) and Debreu (1974) showed is that there is no hope of a general result for stability nor indeed of uniqueness of equilibria, if we wish to build a model based only on individuals who satisfy the standard axioms of rationality.

The full force of the Sonnenschein, Mantel, and Debreu (SMD) result is often not appreciated. Without stability or uniqueness, the intrinsic interest of economic analysis based on the general equilibrium model is extremely limited. Morishima (1964) was very clear, when he said, concerning stability, 'If economists successfully devise a correct general equilibrium model, even if it can be proved to possess an equilibrium solution, should it lack the institutional backing to realize an equilibrium solution, then the equilibrium solution will amount to no more than a utopian state of affairs which bear no relation whatsoever to the real economy.' But, for macroeconomists, uniqueness is also important. 'Comparative statics' in which one compares one equilibrium with another one, predicated on a change in the parameters, makes no sense in the presence of multiple equilibria. Now it is clear why macroeconomists find as the usual way out of this problem the assumption of a 'representative agent' since this obviously generates a unique equilibrium, which will be associated with the prices which make the individual unwilling to move from where he is. However, as I have said, the assumption of such an individual is open to familiar criticisms (Kirman 1992; Stoker 1995) and recourse to this creature raises the basic problem which I have mentioned and which was encountered on the route to the place where general equilibrium has found itself: the problem of aggregation. In fact, we know, as I have already pointed out, that in general, there is no simple relation between individual and aggregate behaviour, and to assume that behaviour at one level can be assimilated to that at the other is simply erroneous. Just to give an elementary example, from the standard assumptions on individuals, it follows that each of their demand for goods satisfy the 'Weak Axiom of Revealed Preference' (WARP); that is, if in some situation, an individual chooses alternative ' $x$ ' when he could have chosen ' $y$ ' he will never choose ' $y$ ' when ' $x$ ' is available. But, unfortunately, if we sum the demands of two individuals, both of whom satisfy WARP, their aggregate demand may not satisfy it. Thus even well-behaved individuals do not, in sum, necessarily have wellbehaved demands. 
Before leaving the general equilibrium model, it is worth noting that the SMD results show the weakness of the model but, not where that weakness comes from. Nevertheless, the damage was done, and many theorists realized just how unsatisfactory the basic model was. What is particularly interesting about that episode is that it was scholars of the highest reputation in mathematical economics who understood the nature of the problem and who brought the edifice down. Indeed, to this day, many economists, usually not pure theorists, continue to use the model as if the SMD results were just a formalistic objection. As a parenthesis, it is just worth remarking that something that plays a key role in macroeconomics, information, was an important ingredient of the insolvability of the stability problem.

The basic market model has been shown to use remarkably little information when functioning at equilibrium. But as Saari and Simon (1978) showed, if there were a mechanism that would take a General Equilibrium economy (Arrow-Debreu) to an equilibrium, that mechanism would require an infinite amount of information. Thus, the stability problem was basically unsolvable in the context of the general equilibrium model. To repeat, starting from individuals with standard preferences and adding them up allows one to show that there is an equilibrium but does not permit one to say that it is unique nor how it could be attained.

With such severe drawbacks, one might wonder why we have persisted with our models based on the General Equilibrium approach. The idea that the economy is essentially in an equilibrium state or on an equilibrium path from which it is sometimes perturbed seems simply to be the wrong departure point. I claim that we have to start from the vision of the economy as a system of interacting agents whose actions, beliefs, and decisions are constantly and mutually influenced. Such a system will self-organize but there is no reason to believe that it will do so into something corresponding to our notion of an equilibrium state and, even should it happen to attain such a state, for the reasons that I have explained, it will not necessarily remain there. It seems perverse to view economic agents as isolated and only linked through an anonymous market. As I have observed, most of the explanations for the current crisis involve a very different view of the economy. The aggregate behaviour of large systems of interactive individuals, molecules, or particles, which are widely studied in other fields, is not typically that of an average or representative member of the population. Again, the very interaction between the individuals changes the aggregation problem and should make us aware of the fact that major changes at the aggregate level can be provoked by small events at the micro level. The fact that we have not done this seems to illustrate a basic tendency in economic theory. As arguments that undermine the models we have built arise, we simply make assumptions which are not 
justified theoretically but which, in effect, make the problems disappear. We persist in clinging to the basic models and making them more mathematically sophisticated whilst overlooking their fundamental flaws. Curiously, it is only the observation of extraordinary empirical phenomena which leads to the questioning of the models and, as Krugman (2009b) has suggested, even this, may not lead to significant changes in the theory. To illustrate this, I will take a look at the basic assumption which underlies much of modern financial economics, the 'efficient markets' hypothesis and suggest that we have witnessed very similar developments. That is, economists have persisted with a model that is theoretically flawed and systematically contradicted by the empirical evidence. Again a quick look at the history of this concept is very revealing.

\section{Efficient markets}

It is sometimes argued that the sort of evolution that we have observed in macroeconomic theory is not paralleled by the evolution of financial economics, simply because the relation between theory and practice was much closer in the latter. This would suggest that, since the theory was continually faced with the acid test of empirical verification, it must have evolved to become more consistent with the empirical evidence. It should become clear, in what follows, that this is not the case. The efficient markets hypothesis, which is at the heart of modern financial economics, says that all the pertinent information concerning financial assets is contained in the prices of those assets. The fundamental idea is that if there were any information other than that contained in prices, some individual could profit from it by an arbitrage. In other words, if someone held information which meant that the change in the price of some asset was predictable he would make money by using that information. Thus the conclusion is that prices must follow an unpredictable path, or what is known as a 'random walk'. This idea was already developed by Bachelier (1900) in his thesis. There is a certain ambiguity here which was present in the original work. Prices contain all the available information because this is incorporated in the demand and supply of those who receive the information. Thus, prices reflect that information. But as Grossman and Stiglitz (1980) argued, if all the information is contained in the price of an asset, nobody would have an incentive to look at their own information and therefore nobody would act on it. As a result the information would never be transmitted into the price. Leaving this problem to one side, what Bachelier argued was that individuals in the market independently observed independently distributed shocks to the system, and this is what constituted their 'information'. His argument was that one could think of the small shocks as random and 
that the sum of such shocks would be normally, or Gaussian, distributed with mean zero. Thus the sum of many small shocks observed independently by the agents would lead to prices following a random walk. What is not clear in his analysis is how, and when, prices are being set for this to work.

What is most interesting is that Bachelier's work went unnoticed for many years and then was taken up with such enthusiasm by economists. Yet, even though this work was to become the very foundation of financial market theory, there were those who, from the outset, saw that the whole structure was unsatisfactory for exactly the reasons that I have suggested are at the heart of our difficulties in macroeconomics. At the time that Bachelier wrote his thesis, Henri Poincaré, the great French mathematician, wrote the thesis report. He clearly stated that one should not take this seriously as a way of modelling financial markets, as individuals do not observe information independently and then act on it, but are constantly influenced by others and will always be prone to herd behaviour. To cite him precisely:

Quand des hommes sont rapprochés, ils ne se décident plus au hasard et indépendamment les uns des autres; ils réagissent les uns sur les autres. Des causes multiples entrent en action, et elles troublent les hommes, les entraînent à droite et à gauche, mais il y a une chose qu'elles ne peuvent détruire, ce sont leurs habitudes de moutons de Panurge. Et c'est cela qui se conserve.

Henri Poincaré quoted in Courtault et al. (2002).

This can be translated as:

When men are in close touch with each other, they no longer decide randomly and independently of each other, they each react to the others. Multiple causes come into play which trouble them and pull them from side to side, but there is one thing that these influences cannot destroy and that is their tendency to behave like Panurge's sheep. And it is that which is preserved. ${ }^{7}$

But Poincaré's warning ${ }^{8}$ went unheeded and, indeed, interest in the area developed by Bachelier waned, and Paul Levy, another well-known

For a complete and entertaining account of this period and the origins and development of the efficient markets hypothesis, see Fox (2009).

8 It is also worth remarking that Poincaré had a correspondence with Walras, the founder of General Equilibrium theory, in which he chided the latter for his assumptions of the 'infinite egoism' and 'infinite farsightedness' of economic agents. The former he could accept, at a pinch, but the latter seemed, at best, implausible. At the very outset of economics' journey down the path to Arrow-Debreu, Poincaré was already pointing out the difficulties, but, unfortunately for economics, his observations fell on deaf ears. 
mathematician, wrote in the margin of Bachelier's thesis, 'Too much on the stock market'. So as Cootner (1967, p. 79), who was the first to give a clear definition of what constitutes the 'efficient market hypothesis', says:

Despite Bachelier's very early interest in stochastic analysis of speculative prices and Working's renewed interest in the 1920's, stock market research from this point on was very slow to develop. While professional practitioners displayed a strong and continuing interest in the stock market, it enjoyed relatively little academic attention until after the debacle of 1929 [emphasis added]. While such lack of attention was not absolute, it stands out very sharply in comparison with the extensive research on commodity prices and on prices of those financial instruments which came under the rubric of "money". This disinterest was compounded of many parts: the smaller role played by organized equity markets in industrial finance, a conviction that stock markets were the product of mass (irrational) psychology akin to gambling, and a shortage, among economists, of the mathematical and statistical skills necessary for effective research in this field.

Note that it was a major crisis in the economy that rekindled interest and, even then, progress was slow until economists in the 1970s rediscovered Bachelier's work. But, consequent upon the introduction of the first analyses based on the efficient markets hypothesis, a series of papers argued that the empirical evidence was in contradiction with the theoretical predictions and that there was 'excess volatility' (for one of the first contributions, see Shiller 1981). A number of individuals showed that the distribution of returns on financial asset exhibited features such as 'fat tails' and 'long memory', ${ }^{9}$ and a particular consequence of modifying the assumptions on the underlying stochastic process was that major upheavals were much more likely than under Bachelier's Gaussian assumptions which had become commonly accepted. What is also interesting is the fact that there was a revival of interest in these 'discrepancies', or put alternatively non-Gaussian phenomena, after the stock market crash of 1987. Thus, it seems that significant changes, at least in financial economics, have been closely related to crises. This was true despite Mandelbrot's persistent calls to turn away from the Gaussian model and use Levy stable distributions. ${ }^{10}$ The Gaussian distribution is, of course, a member of this family but the more general class that Mandelbrot was arguing for, does not allow for the application of central limit theorems and this seriously diminishes the analytical tractability of models built on more

\footnotetext{
Many of these arguments are developed in Teyssiere and Kirman (2006).

10 He started this campaign with little success at the beginning of the 1960s; see Mandelbrot (1962).
} 
general assumptions. What is particularly remarkable is that Eugene Fama, who might be considered as the principle prophet of the efficient markets hypothesis had, as his thesis adviser, Benoit Mandelbrot! The latter has lamented the fact that his best students decided to overlook the basic weaknesses of the Gaussian foundations of financial theory and became more interested in making money than in seeking the truth. ${ }^{11}$ Perhaps even more striking is that Fama himself published a paper in 1965 showing that, without the Gaussian assumption, diversification can actually increase risk. Yet this argument has been put to one side in the later financial literature.

There are two lessons here. First, major crises have stimulated work on the evolution of prices and second, arguments of analytical convenience often prevail even in the face of strong empirical evidence.

It was probably for this second reason that for a long period, the efficient markets hypothesis ruled the roost until the day when Alan Greenspan ruefully admitted before Congress that the 'the whole intellectual edifice collapsed in the summer of last year' Greenspan (2008).

Once again this was the result of a crisis rather than an internal upheaval in theory. One might well ask why this inertia in the theory and, perhaps, more so in practice? The evolution of the practical use of Bachelier's theory is a remarkable illustration of how this can happen. The two most important developments in financial theory with practical applications were, arguably, 'optimal portfolio' theory due to Markowitz (1952) and options pricing with the development of the Black-Scholes formula, (Black and Scholes 1973). Both of these are heavily dependent on the Gaussian assumption. Thus, rather than heeding the warnings of those who argued that empirical evidence was not consistent with this assumption, the development of implementable instruments actually reinforced the dependence on the Achilles' heel of the theory. There is a depressing parallel with the evolution of economic theory. It was not only the theorists, but also those who put the theory into practice, who prevented a thorough reexamination of the theory. In the case of macroeconomic theory, the adoption of the DSGE model by practitioners and the investment in the calibration of those models has meant that there was a strong resistance to questioning their value. Again, the development of a new theory has been retarded by the insistence on, and the embellishment of, the older theory.

There seems to have been no good reason to adhere to the DSGE model and the underlying rational expectations hypothesis other than this being

11 Many of Mandelbrot's criticisms are developed in Mandelbrot and Hudson (2004). 
a satisfactory way to close the model. Both theoretical and econometric considerations should lead us to abandon this approach as Hendry and Mizon (2010) point out. As they say, economies experience intermittent unexpected changes (see Barrell 2001), which may have significant effects on the state of, and operations within, the economic system. They argue that the financial and consequent real economic crisis in 2007-2010 is simply the most recent example. What they suggest is that structural breaks are an inherent feature of the economic system. Indeed, this is precisely what a view of the economy as an evolving, adaptive interactive system would imply. However, the problem is not only with the difficulties that this presents for the participants in the economy who are presumed to be making rational forecasts (see Stock and Watson 1996; Clements and Hendry 2001) but worse, the theoretical underpinnings of the standard macroeconomic models and the way in which they incorporate expectations are also flawed. To quote Hendry and Mizon (2010):

The mathematical derivations of dynamic stochastic general equilibrium (DSGE) models and new Keynesian Phillips curves (NKPCs), both of which incorporate 'rational expectations', fail to recognize that when there are unanticipated changes, conditional expectations are neither unbiased nor minimum mean-squared error (MMSE) predictors, and that better predictors can be provided by robust devices. Further, given the prevalence of such changes, learning about the post-change scenario is both difficult, and itself generates further non-stationarities.

What this says, in summary, is that not only would it be inappropriate for individuals to forecast as they are supposed to in theory but, moreover, it would be very difficult for them to learn to forecast correctly in an environment which is constantly changing. To underline the main message of this article, the very process of learning would lead to further changes in the economy, and there is no reason to believe that the economy would converge to some equilibrium state. The definition of rational expectations needs to be modified and the way in which agents modify their expectations in a world where the environment is changing has to be made explicit. There has, of course, been a substantial literature on this point and it was already very well summarized in Bullard (1991), for example. ${ }^{12}$ The usual starting point for this is that it is unreasonable for agents to make systematic mistakes. Therefore, one would like to argue that,

12 What is particularly surprising is that the most cited articles on this subject are now more than two decades old. 
by learning, agents eliminate their mistakes and come to have a view consistent with the environment. For this to work, and this is the point of Hendry and Mizon's argument, the world has to be a stationary one. If this is not the case, as Bullard was careful to point out, the very idea of 'systematic mistakes' is not well defined. Furthermore, there is no common agreement as to the appropriate learning process and lastly, as Woodford (1990) has shown, it is quite possible for agents to converge to a common agreement on a model which is erroneous, in the sense that they come to believe that some irrelevant variable is driving the evolution of prices.

Up to this point, I have tried to point out some of the reasons for the unhappy evolution of macroeconomics and also of financial economics. However, it would be reasonable to remark that this is all very well, if one has something else to offer. I will now briefly describe a model which incorporates some of the features I have been recommending as essential components of economies and markets.

\section{A model of a financial market}

In Follmer et al. (2005), we develop a model of asset price formation. In that model, the participants in the market can choose between several forecasting rules. The choice of these speculative rules will determine the demands of the various agents and determine the evolution of the equilibrium prices. What is more, these rules turn out to be self-reinforcing. As more people adopt a particular forecasting rule, that rule becomes more accurate and, as a result, more people use it. We give a simple example in which people have a prospect of investing at home or abroad and, what determines the profits to be made is the exchange rate. We suggest two types of rules, one type which we refer to as 'chartist' that involves extrapolating from previous prices. The other is based on the idea that individuals have an idea as to what the 'fundamental' or equilibrium value of the exchange rate is and expect the rate to return to that value and this type of rule we refer to as 'fundamentalist'. The participants in the market are influenced in their choices of rules and hence, in their decisions, by the yields obtained by their past choices and by, of course, the movements of the exchange rate. In this model, self-reinforcing changes in the exchange rate can occur, since as the number of individuals following a rule increases, the success of that rule also increases and hence, as I have said, more people tend to follow it. If the rule is an extrapolatory one, that is 'chartist', then the exchange rate will leave its 'fundamental' value and a 'bubble' will occur. Switches in, and transmission of, expectation formation cause this sort of bubble. 
The self-reinforcing nature of the choices causes people to herd on one particular alternative type of forecast but eventually they will inevitably switch back to another rule. In this case, what is important is that there may be a substantial demand for or supply of the asset in question at a given price even if the underlying fundamentals do not seem to justify this and this will be the case when chartists dominate the market. In switching in this way, market participants are not being irrational. They will have good reason to focus on one opinion, one share, or one currency for a period and then shift to another and we proposed a formal model of the stochastic process, which results from such behaviour, in Foellmer et al. (2005). In this context, it is worth recalling that the horizons of agents in such a market are important. If a trader is judged on his short run gains, he will not be able to take a position based on his long run view of the equilibrium price and this will reinforce the current trend in prices.

Thus, it is the shifting composition of expectations that drives asset movements, or in the model in question, the exchange rate, and this is of course, at variance with the standard model in which expectations are homogeneous and rational. Furthermore, in the latter type of model in theory, no trade takes place. This is at variance with simple empirical observation of the spot market for foreign exchange where approximately $\$ 1.2$ trillion per day was traded in 2001, for example. As Bachetta and Van Wincoop (2003) point out, the obvious explanation lies in the heterogeneity of the agents on the market and, in particular, in the heterogeneity of their expectations. In the standard 'representative agent' model, there is, by assumption, no place for such heterogeneity and many authors have suggested that this is the reason for the poor predictive power of such models [evidence for the latter was already given by Meese and Rogoff (1983), and somewhat more recently by Frankel and Rose (1995) and Cheung et al. (2002)]. Indeed, empirical observations suggest that expectations of actors on financial markets are indeed heterogeneous, (see Chionis and MacDonald 2002). But, the force which drives the appearance of bubbles is that the heterogeneity of the agents' expectations is endogenous and not always present. In fact, for considerable periods, in our model, the great majority of agents have the same expectations so, in one sense, there are periods in which expectations are rational. But periodically expectations shift and before they converge again, there may be considerable heterogeneity.

\section{The structure of interaction: networks}

In the rest of this article, I will suggest one aspect of what should be a feature of macroeconomic models and make a more general 
recommendation. The latter is easy to formulate and I have already alluded to it. We have to base our macroeconomic models on the view that economies are systems of interacting agents and to abandon our view of the behaviour of the aggregate economy as corresponding to that of an individual. But to accept that the interaction between individuals is important requires looking at the nature and structure of that interaction. Economies are not like many particle systems where the particles interact randomly and symmetrically with each other. The structure of interactions between individuals, firms, or banks takes place through a network structure and the nature of the latter, in large part, governs the aggregate outcomes.

Networks and network analysis play a central role in many disciplines and for a long time their role in economics was ambiguous. To many social scientists, the interest of networks must seem evident, since sociologists and political scientists take it for granted that network structures are at the heart of the explanation of social phenomena. However, economists have, until recently, attached less importance to them. For many economists, the study of networks was limited to the analysis of the functioning of physical networks such as the railway, the telephone system, or the internet, for example. Yet, more recently, it has been recognized that networks are, in fact, much more fundamental and pervasive than this and this is well illustrated by Goyal's (2007) and Jackson's (2008b) recent books on economic and social networks. Almost any serious consideration of economic organization leads to the conclusion that network structures both within and between organizations are important. Let me go back for a moment to the crisis of confidence in the world economy. Here we see the role of networks. Bad risks from the American mortgage market had been bundled with good risks into derivatives and these had diffused through the international banking system. Up to that point the financial system, thought of as a network of banks, had become larger and more connected and it was argued that the resultant diversification of risk was a stabilizing influence. Of course, there were those who argued that one had to be more careful in the specification of the network, and that its structure could give clear indications of it fragility (see e.g. Gai and Kapadia 2008). These authors apply random graph techniques to model shocks within a banking network and the aggregated spread of credit contagion. The idea that banks, or countries, are linked to each other and that the links form a network is familiar. If some links exist but are only used with a certain probability, then the network is a random graph. Gai and Kapadia use a directed random graph to model balance sheets concerning a bank's assets and obligations. They show how to model the cascade of contagion effects that can flow through the random graph or the virtual banking network. Yet, in general, there was little analysis of the effect 
of the increasing connectivity of the network or of its other structural features, on the probability of an epidemic of negative impacts. ${ }^{13}$ The problem is, that, as risk is diversified into different instruments those who buy it lose track of the underlying asset. Thus, while the risk is diversified the information is not. When this happens, an epidemic of mistrust can develop as each bank in the network is wary of lending to another who may have inherited the risks that turned out to be bad. Worse, banks find themselves not only with assets which may turn out to be 'toxic' but the market may revise its valuation of all such assets. Thus, the fact that various banks have been obliged to reassess their losses as a result of the subprime episode and its consequences was not only due to their discovering the true nature of their assets but also to the general revaluation of these assets downwards by the market. The resultant losses of the banks enhanced the epidemic of mistrust. Now, it is possible that it is simply the increased connectivity of the network that favoured the development of such an epidemic. This would be an effective counter to those who argued that the effects of shocks have been diminished by globalization. But, in fact, the problem is more subtle than this. Propagation of information or of shocks may be more likely and the effect may be bigger in networks that are much less than fully connected. This would seem to argue against putting the blame on the increasing connectivity of the financial network and in favour of those who maintained that increasing diversification had diminished risks. What exactly is the connection between network structure and the risk of systemic collapse?

This problem was already discussed by Allen and Gale (2000). Using a network structure involving four banks, they showed that the spread of contagion depends crucially on the pattern of interconnectedness between banks. When the network is completely connected, with all banks having exposures to each other such that the amount of interbank deposits held by any bank is evenly spread over all other banks, the impact of a shock is easily absorbed. Every bank suffers a small loss and there is no contagion. By contrast, when the connectivity of the network is lower, with banks only having exposures to a few counterparties, the system is more fragile. The initial impact of a shock is concentrated amongst neighbouring banks. Once these succumb, the premature liquidation of long-term assets and the associated loss of value bring previously unaffected banks into the front line of contagion. Thus, the structure of the network heightens, rather than damps, the effect of a shock. Indeed,

13 Those who were concerned with systemic risk did not study the effect of the properties of the banking network, (see, e.g. Freixas et al. 2000). They thought of banks as being only linked through some central mechanism. 
there is evidence that even in large, apparently anonymous, markets, participants trade or interact with a rather small group of other traders. Thus, the fact that the participants are clustered into limited groups may cause the propagation of a shock which was not particularly large at the outset.

How then can we reconcile this with the fact that the existing financial network has shown itself to be remarkably fragile even though its connectivity has increased over time? One suggestion is that of Giesecke and Weber (2004, 2006). These authors use an interacting particle system called the voter model, which I have already mentioned, as the basis for studying contagion of economic distress between banks. A bank can be in a state of 'high liquidity' or 'low liquidity'. The voter model allows the liquidity state to evolve among the ensemble of banks. However, these authors consider the graph to be the regular square lattice, as if the system was described by a grid of streets as in many US cities, with each bank sitting at an intersection and thus having exactly four neighbours. This is the classical setting for studying the voter model. In this case, the high versus low liquidity banks establish a diffusive boundary between subsets of banks. However, this sort of network does not allow for increasing connectivity since the lattice can become bigger but its connectivity, by many measures, will either not change or may even decrease.

But, even when one allows for increased connectivity, a collapse can still occur as Battiston et al. (2009) show. Thus, as they explain, while it is usually thought that diversification of risk always leads to a more stable financial system, in their model a tension emerges between individual risk and systemic risk. As the number of counterparties in the credit network increases beyond a certain value, the default probability, both individual and systemic, starts to increase. This tension originates from the fact that agents are subject to, what they describe as, a financial accelerator mechanism. In other words, individual financial fragility feeding back on itself may amplify the effect of an initial shock and lead to a full fledged systemic crisis.

This is important because other features of network structure are important here. Degree distribution and centrality also play an important role. The first is simply the distribution of the number of connections with each node and the second is a measure of the importance of a node as a hub in the system. To measure the first means defining the nature of a link from one node to another. For example, in the case of the international financial network, the nodes in Haldane's (2009) presentation correspond to countries and the size of the nodes to the total amount of foreign assets held by the country corresponding to the node in question. A link between countries means that at least one of the two holds the assets of the other. 
Typically one would define a minimum threshold for such assets to constitute the basis for a link. The thickness or weight of the link represents the sum of the mutually held assets. Once these definitions are established, one can calculate the empirical degree distribution and one can see what proportion of the total weight of all the links is made up by the total of the weights associated with the links emanating from the largest nodes. ${ }^{14}$ What we know is that, while the connectivity of the global financial network has increased remarkably in recent years (see Nier et al. 2007), the degree distribution has changed and has become more skewed with a few nodes having very high degree and a group of nodes becoming very central. To quote Haldane (2009) of the Bank of England, when talking about these developments in the banking network before the global financial crisis, he says:

This evolution in the topology of the network meant that sharp discontinuities in the financial system were an accident waiting to happen. The present crisis is the materialisation of that accident.

Haldane (2009, p. 4)

Thus what we have observed is that a network which emerges from a particular evolution of trading relationships which are mutually advantageous can become fragile without those who participate in it realizing what is going on.

The importance of this for economists is clear. Interaction and the networks through which it operates have to be analysed since they play a large role in determining aggregate economic phenomena. This is not the place to develop an argument for network analysis in economics but some things are clear. The first step is to understand how networks, whether stochastic or deterministic, influence aggregate outcomes. The next step is to understand how these networks form and if, and why, they persist. Either one can consider the evolution to be mechanistic according to some criterion of fitness, or one can think of the links in the network as being consciously and strategically chosen by the individuals who constitute the nodes (see recent surveys by Jackson 2007, 2008a).

If we are to move towards better macroeconomics, we will have to incorporate explicitly the idea that the economy is a system of interacting individuals. Second, we have to recognize that the structure of the interaction is important and then to study the consequences of the networks that emerge, for economic activity.

14 Some empirical evidence for the structure of banking networks is given in Khambu et al. (2007). They show that the degree distributions are typically long-tailed and the smaller banks which are more numerous are connected predominantly to the larger ones. 
What sort of theoretical models can help us to understand the role of the network structure in influencing the onset of crises? One approach is developed by May and Arinaminpathy (2009) who study how a downturn in the situation of one bank can propagate and expand through the network. Contributions in the same direction have been made by Economides (1993) and Nier et al. (2007), for example. Here I will briefly present my second example, which is a model which shows how networks and the way in which agents use them can generate large changes in the aggregate state of the economy.

\section{Endogenous bubbles and crashes}

In Anand et al. (2010), we develop a model in which radical changes to the aggregate state can be generated by a very small change in the parameters of that model. We argue furthermore, that changes in parameters that model the structure of a macroeconomy or financial markets are not exogenous but arise as agents adopt rules that appear to be the norm around them. For example, if a rule is adopted by the majority of one's neighbours it will become acceptable or, alternatively, if agents learn that changing their rule leads to greater gains, they will modify their rules. However, as rules develop and spread they may have consequences at the aggregate level which are not anticipated by individuals. These rules may be adopted by implicit consensus as they turn out to be profitable for individuals, but they may also weaken the constraints imposed by regulators. Indeed, the emergence of new rules, or the modification of old ones, may render the whole system more fragile, and it may then cease to function. To illustrate this, we develop a simple model, motivated by the 2007-2008 crisis in credit derivatives markets, to show how coordination on simple and apparently profitable rules may cause a market to collapse.

For the model, we draw from recent accounts on the crisis in credit derivatives which suggest that the diffusion of a certain type of behavioural rules among market participants has played a major role. In brief, two self-reinforcing concomitant factors were at play: on one side, the financial system was becoming less and less transparent. On the other, market participants had fewer and fewer incentives to gather correct information, given the increased costs of information, and the apparent liquidity of the market. Our simple model reproduces this feedback mechanism. In it, the participants in a market for securitized assets when faced with the possibility of buying an asset can choose whether to check on the 'toxicity' of the asset or not. To check is costly but, the risk of not checking is not to be able to sell it to a buyer who does check. To decide what to do, the 
investors sample those with whom they are linked in the market to see if they check or not. If enough of them do not check, individuals are led to buy without verifying the quality of the underlying assets. We show that, as this practice develops, the whole system may finally break down. This will happen if there is a small change in the probability of the asset becoming toxic. In the case of credit derivatives, a small increase in the probability of mortgage default could lead to some investors being induced to check. This in turn will lead others to check and the whole system will switch from an equilibrium where nobody checks the underlying value of assets to one where everyone does so. When this happens, the price of such derivatives drops dramatically, making many market participants vulnerable and others unwilling to lend to them. What is worth noting is that it is the structure of the links between agents that leads them to decide how to act and which causes the rapid change in aggregate behaviour.

This example shows that understanding the structure of the networks that make up the economy is not just an intellectual exercise; it is important for very practical reasons and policy makers are coming to appreciate this. I will leave the last word on this subject to Haldane of the Bank of England:

Deregulation swept away banking segregation and, with it, decomposability of the financial network. The upshot was a predictable lack of network robustness. That is one reason why Glass-Steagall is now back on the international policy agenda. It may be the wrong or too narrow an answer. But it asks the right question: can network structure be altered to improve network robustness? Answering that question is a mighty task for the current generation of policymakers. Using network resilience as a metric for success would help ensure it was a productive one.

Haldane (2009)

\section{The general lesson}

At the risk of being repetitive, let me say again that we have to acknowledge that the direct interaction between agents and the way in which that interaction is organized has fundamental consequences for aggregate economic outcomes. When agents are directly linked to each other and influence each other, the relationship between the behaviour of individuals and the behaviour of aggregate variables will be different from that in the anonymous market situation, in which all agents are linked to each other only through the price system. What we observe at the aggregate level will not mimic what we observe at the individual level, nor will it correspond to the behaviour of some 'representative individual'. Moreover, the rationality which we attribute to economic individuals in order to justify and analyse the behaviour of aggregates may have to be modified. Thus the 
structure of the relationships between individuals, firms, or groups is of profound importance if we are to understand aggregate or macroeconomic behaviour. In the context of the current crisis, a recent UNCTAD report observes:

For many reasons it is wrong to assume that a complex economy, with millions of agents with diverging interests, functions in a way that would be found in a Robinson Crusoe world. Hence, to blame "countries" for their "willingness" to provide "too much savings" compounds the neoclassical error of analysing the world economy based on the expected rational behaviour of "one representative agent". Such an approach cannot do justice to the complexity and the historical uniqueness of events that may lead to phenomena like those that have come to be known as the global imbalances.

UNCTAD (2009).

We should, indeed, be interested in the passage from micro to macroeconomic behaviour, but this cannot be understood without taking into account the way in which individuals', institutions', or countries' decisions and actions are influenced by the networks of connections that link them to other agents. Furthermore, one will not, in general, be able to represent the behaviour of the aggregate as the behaviour of some average or representative individual. Just as neurologists would not think of explaining behaviour by studying the changes in a representative neuron, nor should economists try to explain aggregate phenomena in this way.

This does not mean that one should not be interested in what happens at the micro level, but rather, the passage to the aggregate level is mediated by the network structure in which individuals find themselves. Neurologists will continue to examine what happens at the molecular level but would not argue that there is some simple passage from that level to the aggregate activity of the brain, which does not involve the network of interactions between neurons. As two distinguished scientists in this field, Churchland and Sejnowski (1995), observe:

...while network properties are dependent on the properties of the neurons in the network, they are nevertheless not identical to cellular properties, nor to simple combinations of cellular properties. Interaction of neurons in networks is required for complex effects, but it is dynamical, not a simple wind-up doll affair.

Of course, as economists, unlike neurologists, we do not usually descend as far as the level of the neurons of economic agents, but, as interest in so-called 'neuro-economics' has developed, it has been argued that economic behaviour is very much determined by the network of neurons that is activated in a certain situation and that as the situation changes another 
network may become active. Thus even at this level it is the network structure of the neurons that is important (see Oullier et al. 2008). To return to another analogy, we would not expect how much food is stored by a colony of ants to be explained by looking at the behaviour of individual ants in isolation. The organization of the ants plays an essential role. This example raises an important point. Far from complicating things, taking direct account of interaction and the networks which organize it actually makes life simpler for the economic theorist. This is because the reasoning and calculating capacities we need to attribute to economic agents may be substantially less than it is in standard models. Individuals operating with simple rules in a limited context may, together, generate rather sophisticated behaviour on the aggregate level. In other words, aggregation itself may be what is structuring market or group behaviour.

\section{Regulation}

What I have argued, up to this point, is that the behaviour of the economy, as a whole, cannot be modelled as that of a single individual. Nor should it be considered as a system in equilibrium in the usual sense. The important thing is to recognize that the aggregate dynamics of such systems may have to be considered as 'out of equilibrium'. This poses fundamental problems for their control and regulation. Within the standard macroeconomic equilibrium framework, one calculates the optimal behaviour of the representative individual and the regulatory problem is then to find a set of constraints that will ensure that the resultant equilibrium will have certain desirable properties. Thus, if the model is satisfactory, one can write down a set of rules governing the behaviour of market participants and then create an authority to ensure that the rules are respected. This sort of framework is considered desirable by market actors since, as they say, once we know precisely what the rules are we can choose our optimal actions without having to worry about interference.

Unfortunately, for this regulatory design to be appropriate it is necessary to have an adequate model of the economy and one which, in a general sense, stationary. If this is not the case, the only arrangement for regulation is an authority that monitors the system and tries to detect signs of systemic weaknesses. This was the purpose of 'stress testing' of banks in USA, the success of which has encouraged European countries to adopt similar mechanisms. Once signs of fragility have been detected, the authority will modify the constraints that market participants face in order to prevent the system shifting into an undesired state. The role of such an authority is almost orthogonal to what is necessary for an equilibrium system. In the latter, the rules are fixed and the authority ensures 
that they are respected; in an evolving system, an authority modifies the rules in order to keep the system within acceptable limits. Rather than optimizing subject to fixed constraints, both the constraints and the market participants have to adapt.

Although these may seem like rather abstract considerations it is worth noting that, at the time of writing, in the USA, negotiations are taking place to create an authority, probably led by the Treasury, to identify systemic risk. Such an authority would necessarily diminish the powers of the Federal Reserve, which has been operating by looking violations of rules at the individual institution level. However Chairman Bernanke said, at a hearing in October 2009, that he supported a Treasury-led council, though some of the regional Fed authorities were less welcoming. Furthermore, in a speech in January 2010, he suggested that the Fed itself would move in the same direction for, as he said, it was 'working not only to improve our ability to identify and correct problems in financial institutions, but also to move from an institution-by-institution supervisory approach to one that is attentive to the stability of the financial system as a whole.' Thus there is a growing recognition that the notion of the financial sector and indeed, the whole economy, as a complex adaptive system is the appropriate one. The natural consequence of this is a radical rethinking of the role of regulation and regulators and it seems that this is what is happening, at least in USA. As Representative Barney Frank (New York Times 2010), the chairman of the House Financial Services said:

There will be an entity in charge of systemic risk — which no one now has the responsibility to do - and the consequence of identifying systemic risk will be immediate remedial action to put that institution out of its misery,' (New York Times).

Yet, this goes against the grain for those who have argued for the self-regulation of markets. It is, of course, reasonable to ask, as does Eichengreen (2008), 'how this belief in the efficacy of self-regulation was allowed to develop?' Nevertheless, this concept is now clearly being questioned. While this constitutes a major change of direction, it is unfortunately taking place without a corresponding evolution in macroeconomic theory.

\section{Conclusion}

This brings me to my final point, which is to ask why we are so reluctant to envisage the different models and different tools that I have mentioned. It has been said that we went through the twentieth century developing and perfecting a model based on nineteenth-century physics, but, perhaps in 
the twenty-first century, we could move on to a model based on twentiethcentury physics. However, as Paul Krugman (2009b) has pointed out, the vested interests are strong and to ask economists to take up a new set of tools is probably asking too much. That he is right is well illustrated by the chorus of those now calling for budget tightening and who announce, with confidence, that the crisis is essentially over and that we are now well on the road to recovery. Why should we give credence now to such judgements when the same people making them were so hopelessly wrong in 2007 and 2008? It is surely a desire to return to 'normality' and to carry on building and using models with which we are familiar.

How can this be changed? To discard equilibrium in the standard sense and to move on to study out of equilibrium dynamics is surely the right way to proceed but is perhaps too big a step for economics at the present time. Nevertheless, there are clear indications that there is a tendency to rethink the structure of our theory amongst those who are at the heart of the current crisis. As Bernanke observed when commenting the sudden drop in the Dow Jones index on 6 May 2010:

The brief market plunge was just an example of how complex and chaotic, in a formal sense, these systems have become... What happened in the stock market is just a little example of how things can cascade, or how technology can interact with market panic

Interview with the International Herald Tribune, 17 May 2010

To move away from the standard equilibrium approach, to place externalities, the influence of one person's actions on another, at the centre of the action rather than to regard them as 'imperfections' in our equilibrium model is essential. But, I have maintained here that, if we argue that the interaction between individuals is important, then we have to specify the structure of that interaction. This means that we have to study the structure and fragility of the networks, which govern the interaction between individuals and again to make this central in our analysis and not just a peripheral, albeit fascinating, topic.

For those who find this too radical, one way of looking at the problem would be to suggest that we do not have to abandon our usual notion of equilibria altogether, but what happens is that the system evolves in such a way that the whole financial system and, in particular, the network of banks or countries or even individuals becomes increasingly fragile. In this case, we do not need a major shock to generate a large change in the aggregate state but, even a small shock, can then yield such a change ${ }^{15}$.

15 I am grateful to the referee for this observation. 
While I would prefer to move away completely from the equilibrium notion, others may feel that this alternative is a good compromise. Yet, even this is a considerable change from the standard framework in which a major shock is needed to produce a large shift in the aggregate state. If we go back to the original arguments as to the origins of the crisis in USA, which I have discussed in the introduction, we see that a number of factors are consistently evoked (see, e.g. Pezzuto 2010) among which feature the following:

(i) the low interest rates that prevailed by choice in the US market from 2000 onwards;

(ii) the glut in global savings;

(iii) the high leverage both of institutions and individuals;

(iv) the uncontrolled expansion of innovative financial instruments;

(v) the change in criteria of mortgage lenders, rating agencies, supervisory authorities, and policy makers; and

(vi) the high profitability targets of banks.

Either we see each of these in terms of an exogenous shift, and then consider that their unfortunate coincidence led to market collapse and a radical shift away from equilibrium or we might prefer, as I do, to argue that these are common and co-evolving features of the components of a system which was itself evolving. For example, misperception of risk is also cited as a major factor in the genesis of the crisis. But, in fact, this is a good example of my basic argument. Individuals tried to estimate their individual risk and to act accordingly without taking into account the systemic risk that was being generated by their actions. In this case, there was no equilibrium but the constant evolution of a dynamic system.

Whether one prefers to abandon the standard equilibrium notion and consider disequilibrium dynamics or whether one attributes major aggregate changes to the increasing fragility of the network structure, the standard model has to be changed. Indeed, such changes are essential if we are to progress, but the inertia in the economics profession is strong and whilst the economy has shown that it is capable of sliding rapidly into a new phase, economists may well self-organize to prevent this happening to the profession in the immediate future. But in the end we will move on for, as Max Planck said:

A new scientific truth does not triumph by convincing its opponents and making them see the light, but rather because its opponents eventually die, and a new generation grows up that is familiar with it.

\section{Max Planck A Scientific Autobiography (1949).}




\section{Acknowledgements}

I would like to thank the participants at the Munich conference, at the Bank of England Workshop for Chief Economists of Central Banks, at the University of Edinburgh School of Economics seminar, and an anonymous referee for many helpful comments and suggestions.

\section{References}

Allen, F. and D. Gale (2007), Understanding Financial Crises, Oxford University Press, Oxford.

Anand, K., A. Kirman and M. Marsili (2010), "Epidemics of Rules, Information Aggregation Failure and Market Crashes", European Journal of Finance (forthcoming).

Angner, E. and G. Loewenstein (2010), "Behavioral Economics", in U. Mäki, ed. Handbook of the Philosophy of Science. Philosophy of Economics, Vol. 13, Elsevier, Amsterdam (forthcoming).

Bacchetta, P. and E. van Wincoop (2003), "Can Information Heterogeneity Explain the Exchange Rate Determination Puzzle?", NBER Working Paper No. 9498.

Bachelier, L. (1900), Theorie de la Speculation, Gauthier-Villars, Paris.

Barrell, R. (2001), "Forecasting the world economy", in D.F. Hendry and N.R. Ericsson, eds. Understanding Economic Forecasts, MIT Press, Cambridge, MA, pp. 149-169.

Battiston, S., D. Gatti, D. Gallegati, M. Greenwald, C.N. Bruce and J.E. Stiglitz (2009), "Liaisons Dangereuses: Increasing Connectivity, Risk Sharing, and Systemic Risk", NBER Working Paper Series, Vol. w1561.

Bernanke, B. S. (1983), "Nonmonetary Effects of the Financial Crisis in the Propagation of the Great Depression", American Economic Review 73, 257-276.

Black, F. and M. Scholes (1973), "The Pricing of Options and Corporate Liabilities", Journal of Political Economy 81, 637-654.

Bullard, J. (1991), "Learning, Rational Expectations and Policy: A Summary of Recent Research", Federal Reserve Bank of St. Louis Review 73, 50-60.

Camerer, C., G. Loewenstein and M. Rabin, eds. (2004), Advance in Behavioural Economics, Princeton University Press, Princeton.

Cheung, Y.-W., M. D. Chinn and A. G. Pascual (2002), "Empirical Exchange Rate Models in the Nineties: Are they fit to Survive?", NBER Working Paper, 9393. 
Chionis, D. and R. MacDonald (2002), "Aggregate and Disaggregate Measures of the Foreign Exchange Risk Premium", International Review of Economics and Finance 11, 57-84.

Churchland, P. and T Sejnowski (1995), The Computational Brain, M.I.T. Press, Cambridge, Mass.

Clements, M. P. and D. F. Hendry (2001), "An Historical Perspective on Forecast Errors", National Institute Economic Review 177, 100-112.

Cootner, P. A. (1967), "Origins and Justification of the Random Walk Theory", in P. A. Cootner, ed. The Random Character of Stock Market Prices, MIT Press, Cambridge Mass.

Courtault, J.-M., Y. Kabanov, B. Bru, P. Crepel, I. Lebon and A. Le Marchand (2002), "Louis Bachelier on the Centenary of Théorie de la Spéculation", in J. M. Courtault and Y. Kabanov, eds. Louis Bachelier: Aux Origines de la Finance Mathématique, Presses Universitaires Franc-Comtoises, Paris.

Debreu, G. (1974), “Excess Demand Functions”, Journal of Mathematical Economics 1, 15-23.

Economides, N. (1993), "Network Economics with Application to Finance”, Financial Markets, Institutions \& Instruments 2, 89-97.

Eichengreen, B. (2008), "Origins and Responses to the Current Crisis", CESifo Forum 4/2008.

Fama, E. F. (1965), "The Behavior of Stock-Market Prices", Journal of Business 38, 34-105.

Farmer, D. J. and J. Geanakoplos (2009), "The Virtues and Vices of Equilibrium and the Future of Financial Economics", Complexity 14, 11-38.

Foellmer, H., U. Horst and A. Kirman (2005), "Equilibria in Financial Markets with Heterogeneous Agents: A Probabilistic Perspective", Journal of Mathematical Economics 41, 123-155.

Fostel, A. and J. Geanakoplos (2008), "Leverage Cycles and the Anxious Economy", American Economic Review 98, 1211-1244.

Fox, J. (2009), The Myth of the Rational Market, HarperCollins, New York.

Frankel, J. A. and A. K. Rose (1995), "Empirical Research on Nominal Exchange Rates", in G. M. Grossman and K. Rogoff, eds. Handbook of International Economics, Vol III, North-Holland, Amsterdam.

Freixas, X., B. M. Parigi and J.-C. Rochet (2000), "Systemic Risk, Interbank Relations, and Liquidity Provision by the Central Bank", Journal of Money, Credit and Banking 32, 611-638. 
Gai, P. and S. Kapadia (2008), Contagion in Financial Networks, mimeo, Bank of England, London.

Geanakoplos, J. (2010), "The Leverage Cycle", Cowles Foundation Discussion Paper no. 1715R, Yale University.

Giesecke, K. and S. Weber (2004), "Cyclical Correlations, Credit Contagion, and Portfolio Losses", Journal of Banking and Finance 28, 3009-3036.

Giesecke, K. and S. Weber (2006), "Credit Contagion and Aggregate Losses", Journal of Economic Dynamics and Control 30, 741-767.

Goyal, S. (2007), Connections: An Introduction to the Economics of Networks, Princeton University Press, Princeton.

Greenspan, A. (2008), Testimony to House of Representatives Committee on Government Oversight and Reform, 23 October 2008.

Gromb, D. and D. Vayanos (2002), "Equilibrium and Welfare in Markets with Financially Constrained Arbitrageurs", Journal of Financial Economics 66, 361-407.

Grossman, S. J. and J. E. Stiglitz (1980), "On the Impossibility of Informationally Efficient Markets", American Economic Review 70, 393-408.

Haldane, A. (2009), "Rethinking the Financial Network", Speech delivered at the Financial Student Association, Amsterdam.

Hendry, D. and G. Mizon (2010), "On the Mathematical Basis of Inter-temporal Optimization”, Economics Series Working Papers 497, University of Oxford, Department of Economics.

Ivashina, V. and D. Scharfstein (2010), "Bank Lending during the Financial Crisis of 2008", Journal of Financial Economics 97, 319-338.

Jackson, M. (2008a), "Network Formation", in S. Durlauf and L. Blume, eds. The New Palgrave Dictionary of Economics, 2nd edn., MacMillan Palgrave, London.

Jackson, M. (2008b), Social and Economic Networks, Princeton University Press, Princeton, NJ.

Jackson, M. (2007), "The Study of Social Networks in Economics", in J. Podolny and J. Rauch, eds. The Missing Links: Formation and Decay of Economic Networks, Russell Sage Foundation, New York.

Johansen, J. A. and D. Sornette (2006), "Endogenous versus Exogenous Crashes in Financial Markets", Brussels Economic Review (Cahiers economiques de Bruxelles) 49, Special Issue on Nonlinear Analysis. 
Kambhu, J., S. Weidman and N. Krishnan (2007), "New Directions for Understanding Systemic Risk: A Report on a Conference Cosponsored by the Federal Reserve Bank of New York and the National Academy of Sciences", The National Academies Press, Washington, DC.

Kirman, A. (1992), "What or Whom Does the Representative Individual Represent?", Journal of Economic Perspectives 6, 117-136.

Krugman, P. R. (2009a), The Return of Depression Economics and the Crisis of 2008, W.W. Norton \& Company, New York.

Krugman, P. R. (2009b), "How did Economics Get it So Wrong?", New York Times Magazine, 9 September, pp. 36-44.

Mandelbrot, B. (1962), "Sur Certains Prix Spéculatifs: Faits Empiriques et Modèle Basé Sur Les Processus Stables Additifs non Gaussiens de Paul Lévy", Comptes-Rendus à l'Académie des Sciences, Séance du 4 Juin 1962, 3968-3970.

Mandelbrot, B. and R. L. Hudson (2004), The (Mis) behavior of Markets: A Fractal View of Risk, Ruin, and Reward, Basic Books, New York.

Mantel, R. (1974), "On the Characterisation of Aggregate Excess Demand", Journal of Economic Theory 7, 348-353.

Markowitz, H. (1952), “Portfolio Selection”, Journal of Finance 12, 77-91.

May, R. and N. Arinaminpathy (2010), "Systemic Risk: The Dynamics of Model Banking Systems", Journal of the Royal Society Interface 7, 823-838.

Meese, R. A. and K. Rogoff (1983), “Empirical Exchange Rate Models of the Seventies: do they Fit Out-of-sample", Journal of International Economics 14, 3-24.

Minsky, H. P. (1982), Can 'it' Happen Again? Essays on Instability and Finance, M E Sharpe, New York.

Morishima, M. (1984), "The Good and Bad Uses of Mathematics", in P. J. D. Wiles and G. Routh, eds. Economics in Disarray, Oxford University Press, Oxford.

New York Times (2010), http://www.nytimes.com/2010/02/18/business/ 18regulate.htm (last accessed 18 February 2010).

Nier, E., J. Yang, T. Yorulmazer and A. Alentorn (2007), "Network Models and Financial Stability", Journal of Economic Dynamics Control 31, 2033-2060.

Oullier, O., A. Kirman and J. Scott Kelso (2008), "The Coordination Dynamics of Economic Decision Making: A Multilevel Approach to Social Neuroeconomics", IEEE Transactions on Neural Systems and Rehabilitation Engineering 16, 557-571. 
Pareto, V. (1916), Trattato di Sociologia Generale, 4 vols, Florence: Barbera. (Referred to as Trattato in the text.) Translated into English and edited by Arthur Livingston as The Mind and Society, New York: Harcourt Brace \& Co., 1935.

Pezzuto, I. (2010), "Miraculous Financial Engineering or Legacy Assets?', in R. W. Kolb, ed. Lessons from the Financial Crisis, John Wiley, Hoboken, NJ.

Planck, M. (1949), Scientific Autobiography and Other Papers, Philosophical Library, New York.

Rabin, M. (1998), "Psychology and Economics", Journal of Economic Literature 36, 11-46.

Reinhart, C. M. and K. S. Rogoff (2009), This Time is Different: Eight Centuries of Financial Folly, Princeton University Press, Princeton.

Saari, D. G. and C. P. Simon (1978), "Effective Price Mechanisms", Econometrica 46, 1097-1125.

Schumpeter, J. A. (1950), Capitalism, Socialism and Democracy, Allen \& Unwin, London.

Shiller, R. J. (2003), "From Efficient Market Theory to Behavioral Finance", Journal of Economic Perspectives 17, 83-104.

Shiller, R. J. (2006), "Tools for Financial Innovation: The Neoclassical versus Behavioural Finance", The Financial Review 41, 1-8.

Shiller, R.J. (1981), “Do Stock Prices Move by Too Much to be Justified by Subsequent Changes in Dividends?", American Economic Review 71, 421-456.

Shin, H. S. (2009), "Reflections on Northern Rock: The Bank Run That Heralded the Global Financial Crisis", Journal of Economic Perspectives 23, 101-119.

Shleifer, A. and R. Vishny (1997), "The Limits of Arbitrage”, Journal of Finance 52, 35-55.

Simon, H. A. (1957), Models of Man, Wiley and Sons, New York.

Sonnenschein, H. (1972), "Market Excess Demand Functions", Econometrica 40, 549-563.

Sornette, D. (2003), Why Stock Markets Crash (Critical Events in Complex Financial Systems), Princeton University Press, Princeton, NJ.

Stiglitz, J. E. (2003), The Roaring Nineties: A New History of the World's Most Prosperous Decade, Norton, New York.

Stock, J. H. and M. W. Watson (1996), "Evidence on Structural Instability in Macroeconomic Time Series Relations", Journal of Business and Economic Statistics 14, 11-30. 
Stoker, T. (1995), "Empirical Approaches to the Problem of Aggregation over Individuals", Journal of Economic Literature XXXI, 1827-1874.

Teyssiere, G. and A. Kirman, eds. (2006), Long Memory in Economics, Springer, Heidelberg.

UNCTAD. (2009), The Global Economic Crisis: Systemic Failures and Multilateral Remedies, Report by the UNCTAD Secretariat Task Force on Systemic Issues and Economic Cooperation, United Nations, Geneva and New York.

Von Hayek, F. (1989), "Spontaneous ("Grown") Order and Organized ("Made") Order", in N. Modlovsky, ed. Order: With or without design?, Centre for Research into Communist Economies, London, pp. 101-123.

Von Hayek, F. (1945), "The Use of Knowledge in Society", American Economic Review XXXV, 519-530.

Walker, D. (2006), Walrasian Economics, Cambridge University Press, Cambridge.

Warnock, F. and V. Warnock (2006), "International Capital Flows and U.S. Interest Rates", International Finance Discussion Paper No. 860, International Finance Division, Board of Governors of the Federal Reserve System (September).

Weintraub, E. R. (2002), How Economics Became a Mathematical Science, Duke University Press, Durham and London.

Woodford, M. (1990), "Learning to Believe in Sunspots", Econometrica 58, 277-307. 